anaphylactic reaction to mephentermine and further treatment was initiated along the recommended lines of anaphylatic reaction management using adrenaline as first line of treatment. Adrenaline has $\alpha$ and $\beta$ sympathomimetic actions resulting in peripheral vasoconstriction and increased cardiac output along with bronchodilation. It also inhibits further release of inflammatory mediators from mast cells. ${ }^{5}$

In amended criteria for diagnosis of anaphylaxis 2019, acute onset of hypotension is also considered to be diagnostic of anaphylaxis in a patient known to have exposure to allergen even in the absence of dermatological or respiratory manifestations. ${ }^{6}$ The patient in this case also presented anaphylactic reaction to mephentermine in the form of unresponsive hypotension without respiratory and cutaneous manifestations.

Anaphylaxis is an immunoglobin E (IgE)-mediated lifethreatening systemic allergic reaction leading to activation of mast cells and basophil cells and release of preformed mediators that include histamine, tryptase, carboxypeptidase A, and proteoglycans. These are responsible for different manifestations of anaphylaxis in the form of dermatologic, respiratory, cardiovascular, and neurologic symptoms. ${ }^{7}$ Certain laboratory tests can be performed to confirm the diagnosis of anaphylaxis like skin tests and blood tests for eosinophilia, and to measure levels of immunoglobulin IgE, mast cells, and basophil mediators like enzyme tryptase and histamine. Unfortunately, these tests could not be done in this case and, thus, is a limitation here.

To conclude, the patient had a possible anaphylactic reaction to mephentermine manifesting as hypotension which could be attributed to its constituents mephentermine sulfate and/or to presence of parabens, methylparaben, and propylparaben. Since there is no pre-emptive strategy to know about these unexpected allergic reactions in majority of patients, all necessary equipment and life-saving drugs should always be kept handy.

\section{Conflict of Interest}

None declared.

\section{Acknowledgments}

The author would like to acknowledge Dr. BK Misra, Dr. Alankrita S, and Dr. Ninad D. for their support.

\section{References}

1 Wang CL, Cohan RH, Ellis JH, Caoili EM, Wang G, Francis IR. Frequency, outcome, and appropriateness of treatment of nonionic iodinated contrast media reactions. AJR Am J Roentgenol 2008;191(2):409-415

2 Bhole MV, Manson AL, Seneviratne SL, Misbah SA. IgE-mediated allergy to local anaesthetics: separating fact from perception: a UK perspective. Br J Anaesth 2012;108(6):903-911

3 Bina B, Hersh EV, Hilario M, Alvarez K, McLaughlin B. True allergy to amide local anesthetics: a review and case presentation. Anesth Prog 2018;65(2):119-123

4 Samanta S, Paul M, Samanta S. Mephentermine triggered anaphylaxis in the peri-operative period: an unusual occurrence. Saudi J Anaesth 2013;7(2):219-220

5 Anagnostou K, Turner PJ. Myths, facts and controversies in the diagnosis and management of anaphylaxis. Arch Dis Child 2019;104(1):83-90

6 Turner PJ, Worm M, Ansotegui IJ, et al; WAO Anaphylaxis Committee. Time to revisit the definition and clinical criteria for anaphylaxis? World Allergy Organ J 2019;12(10):100066

7 Arnold JJ, Williams PM. Anaphylaxis: recognition and management. Am Fam Physician 2011;84(10):1111-1118

\title{
Selfie Mode: Handy and Practical Tool to Prevent Horseshoe Headrest Induced Ocular Injury in Prone Position
}

\author{
Rudrashish Haldar $^{1}$ Arun K. Srivastava ${ }^{2}$ Amit K. Verma ${ }^{1}$
}

1Department of Anaesthesiology, Sanjay Gandhi Post Graduate Institute of Medical Sciences, Lucknow, Uttar Pradesh, India

2Department of Neurosurgery, Sanjay Gandhi Post Graduate Institute of Medical Sciences, Lucknow, Uttar Pradesh, India

J Neuroanaesthesiol Crit Care 2021;8:156-157.

Published online June 12, 2020
DOI https://doi.org/ $10.1055 / \mathrm{s}-0040-1712910$ ISSN 2348-0548.

\begin{abstract}
Address for correspondence Arun K. Srivastava, MCh, Department of Neurosurgery, Sanjay Gandhi Post Graduate Institute of Medical Sciences, Lucknow, UP 226014, India (e-mail: doctorarunsrivastava@gmail.com).
\end{abstract}

(C) 2020. Indian Society of Neuroanaesthesiology and Critical Care. This is an open access article published by Thieme under the terms of the Creative Commons Attribution-NonDerivative-NonCommercial-License, permitting copying and reproduction so long as the original work is given appropriate credit. Contents may not be used for commercial purposes, or adapted, remixed, transformed or built upon. (https://creativecommons.org/licenses/by-nc-nd/4.0/).

Thieme Medical and Scientific Publishers Pvt. Ltd. A-12, 2nd Floor, Sector 2, Noida-201301 UP, India 
Prone or ventral decubitus position is frequently employed during neurosurgical procedures involving the craniovertebral junction, cervical, or lumbar spine. Horseshoe headrests are frequently employed to support the patients' forehead and cheeks in the prone position. Horseshoe headrests are well-known to cause pressure injuries like facial, ${ }^{1}$ malar, $^{2}$ and conjunctival injuries. ${ }^{3}$ These injuries are attributed to the pressure effects generated by the weight of the head over the headrest, which is accentuated by the intermittent pressures generated during surgical manipulations. Amongst these, ocular injuries are the most dreaded complications which might lead to postoperative visual loss (POVL) that occurs due to surgery in the prone position along with other reasons like hypotension, embolism, etc. The ASA task force has agreed that horseshoe headrests increases the risk of ocular compression; ${ }^{4}$ therefore, the perioperative caregivers fastidiously attempt to prevent any ocular compression whenever horseshoe headrests are used. Some clinicians prefer pin systems for head fixation to eliminate pressure on the eyes and soft tissues; however, horseshoe headrest is commonly used in neurosurgical practice due to a variety of reasons.

Usual methods to avoid pressure over the eyeballs include the use of commercial eye protectors (Dupaco OptiGuard) and foam headrest, but they themselves might cause eye compression and therefore should be avoided. ${ }^{5}$ Careful positioning of the patients during the initial stages of the surgery and repeated and vigilant observations during the intraoperative period to ensure the eyeballs remain devoid of pressure thus remains the best preventive strategy. Visual inspection of the eyeball necessitates the clinicians to physically bend below the headrest in order to observe the position of the eyeballs, which is ergonomically cumbersome and may not be feasible at all times intraoperatively. In addition, the view obtained, when the clinician is bending below, is at an angle and inaccurate. To ameliorate these limitations, we propose an innovative method. Mobile phones are nowadays ubiquitously available and are camera-equipped. The "selfie" feature is designed to capture pictures in front of the mobile screen. After positioning the patient, the selfie mode of the camera is selected, and the mobile screen is passed below the headrest to provide an exact perpendicular and real-time view of the face of the patient and its relative placement to the frame. (-Fig. 1). Any adjustments which need to be made is then reconfirmed as per the image on the screen. Intraoperatively repeated observations can be made after surgical manipulations are made, fortifying its utility in the dynamic surgical settings. Additional pictures (at 30-minute intervals) can be taken beneath the drapes, causing minimal disturbance. Although nothing can substitute physical verification and clinical judgement, this method adds a safety buffer to avoid potential injuries. In today's era, where emphasis is laid on precise documentation, pictures of the final position

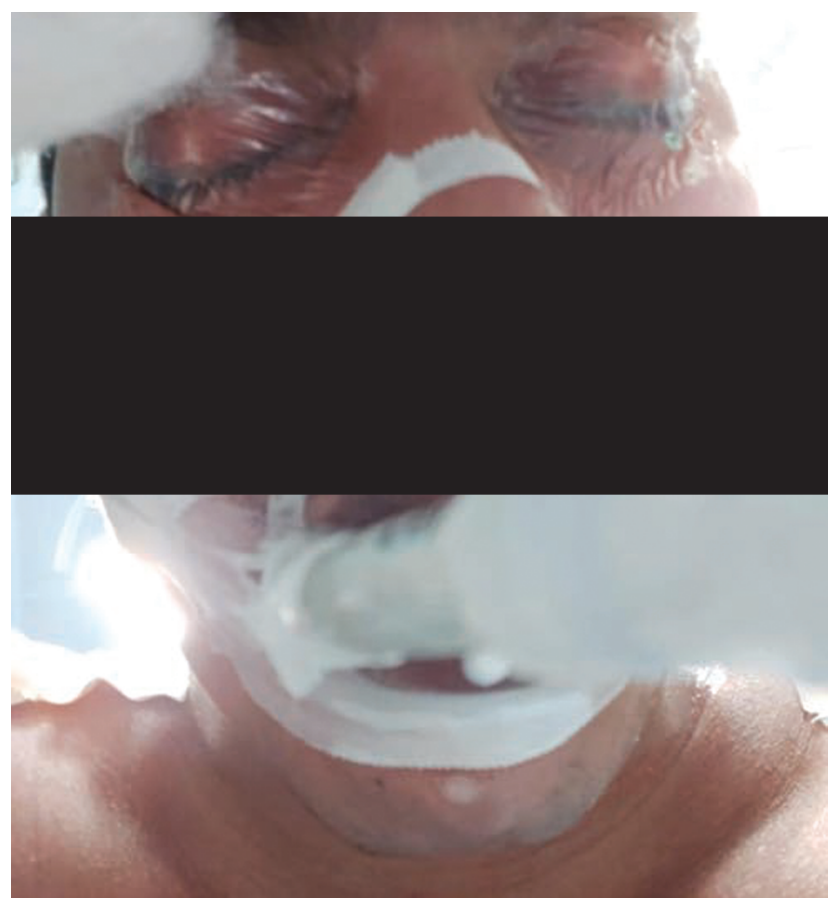

Fig. 1 Photograph of the patient in prone position using "selfie mode" revealing eyes free from pressure.

of the patient prior to draping and repeated pictures intraoperatively serves as a proof should any dispute arise due to inadvertent injuries later. Clinicians should therefore be aware of this technique, in addition to manual and visual inspection to prevent ocular pressure, and include it in their clinical practice.

\section{Conflict of Interest}

None declared.

\section{References}

1 Shamshery C, Haldar R, Srivastava A, Kaushal A, Srivastava S, Singh PK. An unusual cause of unilateral facial injuries caused by horseshoe headrest during prone positional craniovertebral junction surgery. J Craniovertebr Junction Spine 2016;7(1):62-64

2 Jain V, Bithal PK, Rath GP. Pressure sore on malar prominences by horseshoe headrest in prone position. Anaesth Intensive Care 2007;35(2):304-305

3 Cheng MA, Sigurdson W, Tempelhoff R, Lauryssen C. Visual loss after spine surgery: a survey. Neurosurgery 2000;46(3):625630, discussion 630-631

4 American Society of Anesthesiologists Task Force on Perioperative Blindness. Practice advisory for perioperative visual loss associated with spine surgery: a report by the American Society of Anesthesiologists Task Force on perioperative blindness. Anesthesiology 2006;104(6):1319-1328

5 Roth S, Tung A, Ksiazek S. Visual loss in a prone-positioned spine surgery patient with the head on a foam headrest and goggles covering the eyes: an old complication with a new mechanism. Anesth Analg 2007;104(5):1185-1187 